\title{
A INTERSECCIONALIDADE DE GÊNERO, RAÇA E CLASSE EM LIVROS DIDÁTICOS DE EJA
}

\author{
Márcia Alves da Silva (Universidade Federal de Pelotas)* \\ Renata Kabke Pinheiro (Universidade Federal de Pelotas)**
}

\section{RESUMO}

Esta escrita apresenta algumas análises que fazem parte de uma pesquisa maior. Aqui são apresentadas análises de alguns livros pertencentes a uma coleção de livros didáticos voltada à educação de jovens e adultos nos anos finais do Ensino Fundamental. Essa coleção foi aprovada pelo Plano Nacional do Livro Didático (PNLD) e indicada para os anos 2014, 2015 e 2016. Em um primeiro momento, o texto traz um pequeno histórico dos programas de livros didáticos no país para, em um segundo momento, trazer a abordagem dos livros analisados. A intenção é problematizar as representações de gênero que os livros didáticos carregam, compreendendo gênero na sua interseccionalidade com raça e classe social. Em nossa investigação, é possível perceber que, mesmo com os avanços na legislação sobre o tema e da política de avaliação dos livros didáticos, implementada já há algum tempo, e ainda que se percebam avanços no que se refere ao combate à discriminação de gênero, raça e classe, persistem abordagens conservadoras e discriminatórias, mesmo que de forma bastante sutil, o que demonstra a naturalização de desigualdades sociais.

Palavras-chave: Gênero. Classe. Raça. Livros didáticos.

\section{ABSTRACT}

\section{GENDER, RACE AND CLASS INTERSECTIONALITY IN THE TEXTBOOKS OF EJA}

This paper presents some analyses pertaining to a larger research work of ours. In this study, we focus on some textbooks which are part of a series aimed at young people and adults in the final years of primary school education and were approved by the National Plan for Didactic Books (PNLD) for the years of 2014, 2015 and 2016. First, we present a brief history of the didactic programs in Brazil and then, in a second moment, we pinpoint the approach taken in the books under analysis when it comes to gender. Our aim was to problematize the gender representations displayed in the analyzed textbooks, taking into account the intersectionality of gender, race and social class. From our observations, it

\footnotetext{
* Pós-Doutora em Educação pela Pontifícia Universidade Católica do Rio Grande do Sul (PUC-RS). Professora do Programa de Pós-Graduação em Educação da Universidade Federal de Pelotas (UFPel). E-mail: profa.marciaalves@gmail.com

** Doutora em Letras pela Universidade Católica de Pelotas (UCPel). Professora Adjunta do Centro de Letras da Universidade Federal de Pelotas (UFPel). E-mail: rekabke@gmail.com
} 
was possible to notice that despite some progress in the fight against gender, race and class discrimination, and advances in the legislation on the subject as well as in the policy regarding the evaluation of textbooks, conservative and discriminatory approaches still persist - even if in a rather subtle way -, which demonstrates the naturalization of social inequalities.

Keywords: Gender. Class. Race. Textbooks.

\section{RESUMEN}

\section{INTERSECCIONALIDAD DE GÉNERO, RAZA Y CLASE EN LIBROS DIDÁCTICOS DE EJA}

Esta escritura presenta algunos análisis que forman parte de una investigación mayor. Aquí se presentan análisis de algunos libros pertenecientes a una colección de libros didácticos, orientados a la educación de jóvenes y adultos en los años finales de la Enseñanza Fundamental. Esta colección fue aprobada por el Plan Nacional del Libro Didáctico (PNLD) e indicada para los años 2014, 2015 y 2016. En un primer momento, el texto trae un pequeño historial de los programas de libros didácticos en el país para, en un segundo momento, traer el enfoque de los libros analizados. La intención es problematizar las representaciones de género que los libros didácticos cargan, comprendiendo género en su interseccionalidad con raza y clase social. En nuestra investigación, es posible percibir que, a pesar de los avances en la legislación sobre el tema y la política de evaluación de los libros didácticos, implementada desde hace algún tiempo, aunque se percibe avances en lo que se refiere al combate a la discriminación de género, raza y clase, todavía persisten enfoques conservadores y discriminatorios, aunque de forma bastante sutil, lo que demuestra la naturalización de desigualdades sociales.

Palabras clave: Género. Clase. Raza. Libros didácticos.

\section{Introdução}

Este artigo transita entre as políticas dos programas de produção e distribuição de livros didáticos para a rede de ensino pública do Brasil e as abordagens de gênero que esses livros contêm. Dessa forma, este texto traz algumas análises que fazem parte de uma pesquisa maior, denominada Representações de gênero em livros didáticos (SILVA; PINHEIRO, 2014). As autoras do texto, além de pesquisadoras na área de gênero e feminismos, também são docentes em cursos de licenciatura, atuando, portanto, diretamente com formação de professores(as). No que se refere à formação inicial e continuada de professores e professoras, esta proposta se sustenta pela necessidade de os/as docentes se apropriarem das representações de gênero que os livros didáticos trazem, já que essas se constituem numa importante ferramenta de trabalho docente, que fazem uso constantemente desses materiais nos processos de ensino-aprendizagem que implementam em sua rotina de trabalho. Dessa forma, é inegável que os livros didáticos exercem uma importante influência na formação dos e das estudantes, na constituição cultural e social dos cidadãos e cidadãs.

Sendo assim, este texto busca problematizar as representações de gênero trazidas em livros didáticos, especialmente em livros da educação de jovens e adultos. Trata-se de uma investigação que está em andamento, mas da qual já é possível se fazer algumas inferências sobre a caminhada feita até o momento. 
Para dar conta da proposta, o estudo almeja aproximar e dialogar com campos distintos, como a Educação e os Estudos de Gênero. Aposta-se na construção de um campo de pesquisa que permita, a partir da análise dos livros didáticos, identificar as compreensões sobre gênero que estes trazem em seu âmago, no que se refere a vários aspectos, como família, relações sociais, trabalho, formação etc., constituindo-se, dessa forma, as categorias de estudo.

Aqui serão apresentadas as análises de cinco livros que fazem parte de uma coleção de livros didáticos voltados à educação de jovens e adultos nos anos finais do Ensino Fundamental. Essa coleção foi aprovada pelo Plano Nacional do Livro Didático (PNLD) e indicada para os anos 2014, 2015 e 2016.

Os estudos que estamos desenvolvendo ancoram-se numa perspectiva feminista advinda dos estudos de gênero e buscam uma aproximação com as abordagens de gênero que os livros trazem em seus conteúdos e formas, incluindo aí os textos e as imagens que os compõem. Importante ressaltar que aqui percebemos gênero de forma interseccional com outros marcadores sociais, como etnia/raça e classe. Sobre a importância dos livros didáticos, Marques (2006) levanta algumas reflexões que precisamos ter em mente quando nos aproximamos desse objeto de estudo, demonstrando a complexidade do tema. Para ela,

O livro didático, como expressão de um certo conhecimento, está inserido no bojo de um contexto mais amplo, por vários motivos: porque visa a formação/educação de um 'cidadão' apto a se ajustar e a contribuir para uma sociedade 'moderna'; porque reflete a forma como esta sociedade pensa a si mesma em termos de sua constituição histórica - o que se refere a uma certa memória oficial, em termos de seu funcionamento, de sua dinâmica social e, por fim, em termos de seu destino histórico rumo ao futuro; e também porque o livro didático faz parte, enquanto mercadoria, de uma indústria cultural que precisa reproduzir-se enquanto empresa. De forma que o livro didático está inserido, ao mesmo tempo, no mundo moderno da cultura, do trabalho, da tecnologia e do consumo. (MARQUES, 2006, p. 211, grifo do autor).
0 percurso do artigo faz, num primeiro momento, um pequeno resgate do histórico dos programas de livros didáticos no país para, num segundo momento, trazer a abordagem dos livros analisados, sempre com a intenção de problematizar as representações de gênero que os livros didáticos carregam, compreendendo gênero na sua interseccionalidade com raça/etnia e classe. Para isso, faz-se uso de aspectos advindos da metodologia da análise de conteúdo (FRANCO, 2012), com o intuito de auxiliar no exercício de coleta de dados e de escolha das categorias de análise, visando qualificar o olhar para selecionar os aspectos realmente importantes, para se chegar, dessa forma, à análise dos dados.

\section{Sobre o Plano Nacional do Livro Didático (PNLD)}

É importante sabermos que programas destinados à distribuição de obras didáticas aos estudantes da rede pública de ensino brasileira não são nada novos. Na verdade, programas desse tipo existem no Brasil desde 1929. ${ }^{1}$ No entanto, na sua versão atual, o PNLD vem sendo executado desde 1996.

Na sua criação, na década de 1980, o PNLD visava melhorar a qualidade do livro didático (incluindo a qualidade gráfica), passando-se a utilizar livros não descartáveis, visando-se organizar, inclusive, bancos de livros didáticos nas escolas. Nessa época, havia a preocupação de que o Programa mantivesse a autonomia, não permitindo a influência das grandes editoras. Para isso, o governo chamou diversos movimentos sociais que, na época, já faziam críticas aos livros didáticos. Em 1987, foram assinados protocolos com lideranças representativas do movimento de mulheres e do movimento negro (SILVA; TEIXEIRA; PACÍFICO, 2014).

Na década de 1990, pode-se dizer que, de certa forma, as demandas históricas dos movimentos sociais são incorporadas em cri-

1 Para um histórico mais detalhado do PNLD, ver Ministério da Educação (2013). 
térios de avaliação dos livros didáticos, com a publicação de Definição de Critérios para Avaliação dos Livros Didáticos (BRASIL, 1994), em 1994. Os temas racismo e sexismo aparecem explicitados no documento, demonstrando a preocupação com formas de discriminação que os livros poderiam conter. Entretanto, ao mesmo tempo que poderíamos comemorar a elaboração de critérios avaliativos para esse importante material pedagógico, nessa mesma época se percebe um distanciamento dos movimentos sociais, que passam a ser excluídos de participação nesse debate, sendo desconsiderados. Em tempos de implantação do estado neoliberal no país, passa-se a ter maior participação de editores e autores nas políticas dos livros didáticos. É nesse contexto que é implementada a primeira avaliação dos livros, em 1996.

No que se refere ao Ensino Médio, apenas em 2005 o PNLD começa a distribuição de livros didáticos para este nível de ensino, sendo contempladas, na primeira fase, apenas as disciplinas de língua portuguesa e matemática. Apenas em 2010 foi incorporada ao Programa a Educação de Jovens e Adultos.

Sobre a compra dos livros didáticos pelo governo, desde os anos 1990, esse procedimento tem ocorrido por meio de editais, incorporando mais aspectos relacionados com a diversidade e a promoção da igualdade apenas a partir do edital de 2007, em que o texto afirma como princípios do processo de ensino-aprendizagem.

\section{Abordagem de gênero nos livros didáticos de EJA}

Na área de educação, é sabido que a modalidade de Educação de Jovens e Adultos (EJA) possui suas particularidades, pois se trata de uma categoria de discentes adultos e que, por isso mesmo, chegam na instituição escolar com uma bagagem social, cultural, linguística e intelectual que não pode ser ignorada. Essa característica coloca alguns temas como pauta fundamental desses estudantes jovens e adultos, como trabalho e profissão, família, política, gênero, entre outros.

Aqui há interesse pelas abordagens de gênero que são apresentadas nos livros didáticos de EJA, incluindo as imagens e os textos escritos constantes no material. Conforme Franco (2012), compreendemos que o ponto de partida da análise de conteúdo é a mensagem, seja ela oral, escrita, documental, figurativa etc., percebendo-a como elemento que expressa as representações sociais, na qualidade de elaborações mentais construídas socialmente, numa relação que se dá na história da humanidade e que tem implicações na vida cotidiana, influenciando diretamente os comportamentos. Dessa forma, a análise de conteúdo

[...] assenta-se nos pressupostos de uma concepção crítica e dinâmica da linguagem. Linguagem, aqui entendida, como uma construção real de toda a sociedade e como expressão da existência humana que, em diferentes momentos históricos, elabora e desenvolve representações sociais no dinamismo interacional que se estabelece entre linguagem, pensamento e ação. (FRANCO, 2012, p. 13).

Trabalhamos a investigação na perspectiva desenvolvida por Rosenthal (2014), denominada Pesquisa Social Interpretativa. Esta autora ressalta que as pesquisas qualitativas, historicamente, têm oscilado entre dois polos: quantitativo e qualitativo. Dessa forma, a pesquisa social interpretativa possui sua origem na diferenciação entre os paradigmas normativo e interpretativo: enquanto no paradigma normativo se compreende o indivíduo como organismo que reage de forma adaptativa a um sistema simbólico compartilhado, o paradigma interpretativo concebe as pessoas como organismos ativos, de modo que o indivíduo não surge como adaptado ao mundo ou reagindo a ele, mas como produtor da realidade social a partir da interação social com seus pares (ROSENTHAL, 2014). Assim, essa última perspectiva compreende que as representações sociais se constituem em processos interativos e se transformam continuamente na sociedade. É 
dessa forma que percebemos as abordagens de gênero apresentadas nos livros didáticos e, por isso, nossa metodologia não concebe a pesquisa de forma fechada, engessada em métodos e instrumentos quantitativos, mas, sim, buscando compreender a realidade social nas suas múltiplas facetas. Para isso, é necessário que se perceba o processo investigativo de forma dinâmica e aberta ao uso de diversas técnicas e instrumentos, incluindo a sensibilidade de quem pesquisa. Assim, o método de análise de conteúdo pode se constituir numa ferramenta metodológica poderosa, considerando-se a pesquisa qualitativa e de forma interpretativa.

Rosenthal (2014) identifica, ainda, dois objetivos principais da pesquisa social interpretativa: a apreensão do sentido subjetivamente visado e a reconstrução do sentido latente. Por sentido subjetivamente visado não devemos entender como processos privados ou apenas individuais, mas, pelo contrário, as representações sociais são construídas a partir da apropriação de conhecimento construído no processo de socialização. Por sentido latente ou significado objetivo de um texto não se deve compreender somente aquilo que nos é aparente, mas entender que, em termos de sentido, produzimos muito mais do que nos é acessível, por intermédio de ideologias, mitos etc., produzidos em variados contextos sociais e períodos históricos.

$\mathrm{Na}$ proposta desenvolvida pela pesquisa social interpretativa, “[...] a interpretação de um texto visa à reconstrução de seu significado social geral" (ROSENTHAL, 2014, p. 26). 0 texto nos leva a uma grande gama de elementos, pois se refere a todas as formas de expressão produzidas na interação social, que são ou podem ser protocoladas de alguma forma. Aqui podemos entender os livros didáticos e, mais especificamente, os elementos que os constituem, como textos, incluindo aí a produção escrita e as imagens que esse material reproduz.

Os livros analisados aqui fazem parte da coleção Alcance Eja, para os anos finais do Ensino Fundamental. A coleção é publicada pela Editora Positivo e indicada pelo PNLD para os anos 2014, 2015 e 2016. Cinco obras fizeram parte do nosso estudo, em que cada uma representa uma área de conhecimento. São elas: Artes, História, Geografia, Ciências e Matemática (DOMINGUES, 2013; DUDEQUE; SAMPAIO, 2013; GRITTEM, 2013; LOBO, 2013; SCHLICHTA; AZOUBEL; ROMANELLI, 2013).

Figura 1 - Exemplares da coleção de livros didáticos Alcance Eja

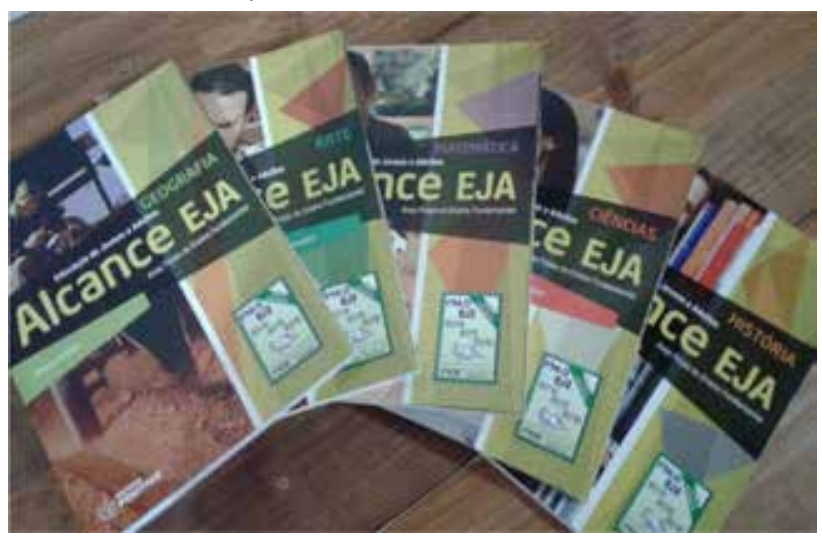

Fonte: Acervo pessoal das autoras.

$\mathrm{Na}$ abordagem dos livros, procuramos identificar elementos, tanto textuais como imagéticos, que se referissem, de forma tanto latente como subjetiva, à temática de gênero, incorporada nos mais diversos marcadores sociais, principalmente de classe e raça/etnia. Dessa forma, mergulhamos nos temas abordados nos livros analisados e exibimos aqui parte dos resultados obtidos, que apresentaremos de acordo com cada área de conhecimento trazida pelos livros.

\section{Sobre o livro de ciências: a invisibilidade das mulheres cientistas e suas presenças/ ausências no mundo do trabalho e no aspecto geracional}

Toda a coleção apresenta na capa a imagem de uma pessoa, em um ambiente específi- 
co. A capa do livro de ciências (DUDEQUE; SAMPAIO, 2013) é ilustrada com uma grande fotografia de uma mulher branca jovem, vestindo um jaleco, presente em um ambiente que contém medicamentos, onde eles aparecem em primeiro plano na imagem. A mulher manuseia os medicamentos. Podemos inferir que a imagem nos remete à ideia de profissões e/ou atividades ligadas ou pertencentes à área da saúde. A imagem já nos passa uma mensagem por si só: de que mulheres atuam nesta área, delineando, dessa forma, o lugar da mulher. Sabemos que estudos na área do trabalho já mostram o quanto profissões ligadas ao cuidado são majoritariamente femininas, pois, historicamente, têm sido exercidas por mulheres. A área da saúde é exemplo dessa situação.

Ao longo dos diversos capítulos do livro, são apresentados importantes pesquisadores, em diversas áreas, como física, química etc. São apresentadas fotos dessas pessoas que vão aparecendo ao longo do livro, de acordo com os temas tratados e suas descobertas. Salta aos olhos que os cientistas apresentados são todos homens. Isso pode levar à ideia de que essa profissão só deve ser exercida por homens e não por mulheres. No entanto, sabemos da importância de diversas mulheres no desenvolvimento da ciência. Schienbinger (2001) já anunciava a importância da participação das mulheres na ciência e denunciava sua invisibilidade.

Diversas obras recentes têm procurado fazer um mapeamento a fim de valorizar e visibilizar as inúmeras mulheres cientistas que deixaram seu legado a diversas áreas de conhecimento ao longo da história da ciência. Um exemplo bem recente disso diz respeito à obra de Ignotofsky (2017), que traz uma biografia de 50 mulheres cientistas. Outra obra a ser destacada é de autoria de McGrayne (1994), que traz biografias de mulheres ganhadoras do Prêmio Nobel de Ciências, destacando suas trajetórias no mundo da ciência, abarcando o preconceito do qual foram vítimas.
No que se refere às imagens apresentadas no livro analisado, é visível a imensa maioria de imagens masculinas, tanto em desenhos como em fotografias, e nas mais diversas situações, tanto quando querem apresentar algum órgão do corpo humano e o representam em um desenho, como quando querem ilustrar uma pessoa exercendo uma atividade, na agricultura por exemplo. Quanto à linguagem utilizada no livro, esta também é masculinizada. Nomenclaturas como "os indivíduos", "o ser humano" e "o personagem" são majoritárias.

No entanto, em cada capítulo há seções denominadas Refletir e debater, que apresentam textos curtos, curiosidades e matérias jornalísticas ou documentários. Nessa parte, diversas vezes são apresentados textos de autoria feminina.

O Capítulo 1, que faz parte da primeira unidade do livro, denominada Conhecendo o Universo, aborda a Astronomia como ciência que estuda os astros. Chama atenção o fato de que a metade do capítulo é matéria relativamente extensa, tratando da astronomia indígena, o que demonstra que há um compromisso de tratar-se de diversas culturas, incluindo as culturas menos hegemônicas e que sabemos, historicamente, são mais excluídas e discriminadas, como a indígena.

Há uma grande preocupação com a abordagem sobre o meio ambiente. Esse tema, voltado à ecologia, permeia praticamente todo o livro. Ainda na primeira Unidade do livro, são apresentados conceitos como sustentabilidade e desenvolvimento sustentável, e dados e relatórios do Rio +20 foram mostrados. 0 livro possui uma unidade (unidade 3 ) denominada Ecologia, contendo diversos capítulos sobre o tema.

Há uma preocupação com a água, como recurso esgotável e finito. Esse tema aparece em diversos capítulos ao longo do livro. Já na primeira unidade, a água aparece em hidrelétricas, e o processo de chuvas e a forma como a Amazônia interfere no clima é desenvolvido. Aqui é impossível esquecer do nome da bióloga marinha Sylvia Earle (PEGURIER, 2015), 
que dedicou toda a sua carreira na defesa dos oceanos, lutando contra a pesca predatória, o que faz até hoje. Seu compromisso com a vida marinha e com a preservação do ecossistema tem sido mundialmente reconhecido. No entanto, no livro de ciências da coleção pesquisada (DUDEQUE; SAMPAIO, 2013), embora o tema da água e da preocupação com o meio ambiente seja recorrente, o nome de Earle não é mencionado.

Na Unidade 4 - Conhecendo nosso corpo: organização e funcionamento - chamou atenção uma matéria colocada na seção Refletir e debater (DUDEQUE; SAMPAIO, 2013, p. 201). Essa matéria é um trecho extraído de uma publicação do Ministério da Educação, Secad, 2016, que tem como título Vida Nova aos 60: na terceira idade, mulheres procuram emprego que dê estabilidade. Essa matéria, da forma como foi colocada na obra, ficou totalmente solta, descontextualizada, pois aborda um exemplo de uma mulher que ingressou no mercado de trabalho formal aos 66 anos, após uma vida inteira de trabalho na informalidade, como vendedora de produtos de porta em porta. A matéria tem como objetivo ressaltar a importância da produtividade na terceira idade, reforçando o caráter produtivo das pessoas, tanto homens como mulheres, nesta fase da vida. No entanto, percebe-se que várias lacunas ficaram sem problematização, pois o exemplo dado deixou em aberto uma série de questões, como: por que essa mulher ficou fora do mercado de trabalho formal por tanto tempo? 0 que houve para que isso acontecesse? Se fosse um homem, seria da mesma forma? Embora a matéria trate de uma mulher, a questão de gênero simplesmente foi invisibilizada; apenas usaram o exemplo ressaltando a questão geracional, por se tratar de uma pessoa na terceira idade, independentemente de ser uma mulher ou um homem. Sabemos que a questão de gênero se impõe fortemente no que se refere ao mundo do trabalho, e isso passou ao largo, mesmo sendo um tema importante para o/a discente de EJA.
Diversas pesquisas realizadas no Brasil vêm demonstrando as especificidades da participação das mulheres no mercado de trabalho, tanto formal como informal. Como exemplo, podemos citar o Relatório Anual Socioeconômico da Mulher (RASEAM) (MINISTÉRIO DA MULHER, DA FAMÍLIA E DOS DIREITOS HUMANOS, 2015) e relatórios do Instituto Brasileiro de Geografia e Estatística (IBGE), relativos à temática de gênero (INSTITUTO BRASILEIR DE GEOGRAFIA E ESTATÍSTICA, 2017).

Ainda sobre a questão geracional, o Capítulo 12, denominado Sexualidade e Saúde, traz novamente esse tema, quando aborda as diversas fases da vida, desde o nascimento, passando pela infância, adolescência, fase adulta e velhice. Chama atenção a denominação utilizada a respeito da velhice, pois, no texto, a velhice é conceituada como "senilidade". 0 termo, como sabemos, traz em seu âmago o significado de debilidade e doença. No entanto, com a intenção de combater o preconceito e de fomentar a valorização da velhice, as autoras afirmam que "[...] por tudo o que já fez, pelas experiências pelas quais passou e pelo conhecimento adquirido, o idoso deve ser valorizado e respeitado" (DUDEQUE; SAMPAIO, 2013, p. 235). Dessa forma, demonstra-se a fragilidade nos argumentos em prol da valorização da pessoa idosa, pois o argumento remete apenas ao passado daquela pessoa, como se no presente devêssemos nos penalizar e sensibilizar pelo que essa pessoa foi e fez na sua vida, e não pelo que ela é e faz, simplesmente.

Assim, o que podemos perceber é que o texto acaba por reforçar, mesmo que essa não tenha parecido ser a intenção, os estereótipos hegemônicos sobre a velhice, o que é lamentável, haja vista que se trata de discentes de EJA, e que esse tema deveria ser melhor explorado e problematizado, pois estamos lidando com pessoas que já haviam sido excluídas da instituição escolar e que a questão etária passa a ser um elemento importante a ser discutido.

No entanto, chama atenção que, na mesma página, numa seção chamada Refletir e Deba- 
ter, é sugerido um debate na turma a partir de duas questões apresentadas, que são: como acontece a divisão de papéis em sua família? e Existem diferenças entre os papéis que homense mulheres desempenham na sociedade? (DUDEQUE; SAMPAIO, 2013, p. 235). Embora deva-se admitir que a temática é importante e necessária, as duas questões ficaram soltas no capítulo. Neste caso, cabe ao docente encaminhar uma dinâmica apropriada com essas questões.

Ainda no capítulo 12, que trata de sexualidade, é interessante perceber que, além de abordar a constituição biológica dos órgãos sexuais, no livro se materializa a preocupação de ampliar o tema da sexualidade para além da constituição biológica das pessoas. Na seção denominada Para Saber Mais, é tratado o tema homofobia, trazendo um conceito e aspectos da Lei no 10.948, que criminalizam a homofobia, caracterizando-a como ato discriminatório passível de punição legal (DUDEQUE; SAMPAIO, 2013 , p. 236). Isso demonstra uma preocupação das autoras em opor-se ao sexismo, demonstrando, assim, um compromisso com o combate ao preconceito de gênero.

\section{Sobre o livro de história: entre a valorização dos movimentos sociais e políticos e a invisibilidade das imagens femininas}

O livro trata da história do Brasil desde antes da chegada dos portugueses até a contemporaneidade (LOBO, 2013). De início, já é possível perceber a pretensão de lidar com tão vasto tempo histórico em apenas um livro. Isso demonstra a dificuldade de se aprofundar qualquer tema proposto. Mesmo assim, é possível fazer algumas inferências sobre o material.

A capa do livro de história da coleção é ilustrada com uma grande fotografia de uma pessoa jovem, segurando um livro nas mãos, em uma biblioteca. Toda a coleção apresenta na capa a imagem de uma pessoa, em um ambiente específico. No caso do livro de história, a capa apresenta a imagem de um homem branco, jovem.

Em primeiro lugar, salta aos olhos a participação de indígenas e africanos, além da presença dos portugueses na construção da identidade nacional. A Unidade 2 tem como título "Cultura, diversidade e identidade nacional" e busca mostrar as diversas culturas étnicas e sua presença na construção da identidade do país. É visível que há uma preocupação em incorporar as etnias negra e indígena, e não de forma mascarada, mas assumindo os conflitos que houve entre os diferentes grupos. A Unidade 4, denominada "Brasil: terra, trabalho e poder", desenvolve o tema da ocupação do território pelos portugueses e do desenvolvimento da sociedade colonial, salientando o processo de escravidão dos povos indígenas e africanos, abordando os processos de resistências desses povos ao domínio português, o que deixa muito claro que "a escravidão não foi aceita passivamente, nem por indígenas, nem por africanos" (LOBO, 2013, p. 86), desmistificando a ideia conservadora e amplamente difundida em nossa cultura de que a escravidão foi um processo pacífico e de aceitação e conformidade dos grupos envolvidos. Dessa forma, vemos ser ultrapassada a conservadora visão dos povos tradicionais como submissos, abordagem que era muito comum na História escolar.

De forma geral, os movimentos sociais e os conflitos por luta de poder são contemplados no livro. Exemplo disso é a Unidade 6, que tem como título "A República e as mobilizações sociais", e na parte que trata da república do café com leite, há um capítulo específico sobre os movimentos no campo e na cidade (capítulo 20). Além disso, quando aborda o Segundo Reinado, trata do tema abolicionista e, no período da Ditadura Militar, aborda o movimento pelas eleições diretas para a presidência.

Sobre as mulheres, o capítulo desta Unidade, que aborda a Era Vargas (de 1930 a 1945), 
possui uma seção denominada "A conquista do voto feminino", dando destaque ao movimento sufragista no país. Em uma matéria relativamente longa (de quase duas páginas, considerada longa para um livro didático), a advogada Bertha Lutz é citada como liderança nesse período, assim como são nomeadas as primeiras mulheres eleitas em espaços políticos, como a primeira prefeita eleita no Brasil e na América Latina, Luiza Alzira Soriano Teixeira.

No que se refere à veiculação de figuras femininas nas imagens apresentadas no livro, elas são muito escassas em comparação com as imagens em que aparecem homens. Basicamente, são apresentadas duas: a primeira na página 11 , que, em capítulo que trata sobre o tempo, uma imagem aborda as fases da vida de uma pessoa, e traz mulheres negras em todas as fases (infância, juventude, maturidade e velhice), contendo, portanto, quatro mulheres com idades diferentes, isto é, cada uma representando uma fase. A outra imagem é apresentada na página 86, que traz o detalhe de uma pintura de Antônio Parreiras, denominada Os Invasores, de 1936. A pintura representa a captura de indígenas pelos portugueses e apresenta uma mulher indígena capturada. 0 que chama atenção é a branquitude da mulher apresentada na pintura, o que se afasta muito da raça indígena.

\section{Sobre as abordagens trazidas no livro de Geografia: a valorização dos povos tradicionais e as mulheres entre a casa e o trabalho}

A capa do livro é ilustrada com uma grande fotografia de um trabalhador, ou uma trabalhadora, pois não ficou nítido na imagem se se refere a um homem ou a uma mulher (GRITTEM, 2013). 0 que aparece nitidamente é que se trata de um(a) trabalhador(a) rural, que está sentada em uma grande máquina agrícola (pode ser um trator, uma colheitadeira ou algo do tipo), com o rosto coberto por um pano, possivelmente se protegendo de algum defensivo agrícola ou do pó produzido pela máquina em movimento, já que a poeira do solo é visível na imagem. Toda a coleção apresenta na capa a imagem de uma pessoa, em um ambiente específico. No caso do livro de geografia, a capa apresenta a imagem de uma pessoa trabalhando na terra.

No livro de geografia da coleção, podemos fazer alguns destaques. Um deles se refere a uma unidade denominada "O povo brasileiro". Essa unidade é formada por quatro capítulos que tratam da identidade e da cultura brasileira, com um capítulo sobre as comunidades indígenas e quilombolas, destacando, dessa forma, as comunidades tradicionais. Ainda nesta unidade, um dos capítulos apresenta dados sobre a população do país, abordando mudanças recentes na constituição das famílias, que têm tido sua formação diminuída, tornando-se menos numerosas, por exemplo. Há uma pequena seção chamada Refletir e Debater, que aponta como causas da redução da taxa de nascimentos "o uso de anticoncepcionais, a inserção da mulher no mercado de trabalho e o aumento da escolaridade feminina" (GRITTEM, 2013, p. 103), todas características diretamente relacionadas às mulheres. Podemos inferir que, mesmo muito sutilmente, um tema importante referente às mulheres apareceu pautado nessa unidade.

Outro elemento que chama atenção sobre a incorporação da temática feminina no livro de geografia da coleção aparece na Unidade 10, que tem como título "Distribuição da população mundial", em um capítulo específico sobre as mulheres, denominado "O papel feminino na sociedade globalizada”. Este capítulo, basicamente, aborda a participação das mulheres no mundo do trabalho, mostrando dados que apontam a disparidade da situação de emprego e salário das mulheres, destacando dados que mostram os menores salários das mulheres no mercado de trabalho. A autora afirma a discriminação e a violência que as mulheres sofrem, 
mas apenas como um tímido destaque, pois o capítulo se limita ao mercado de trabalho.

\section{Uma abordagem "realista"? As representações de gênero no livro de Matemática}

A capa do livro de matemática é ilustrada com uma grande fotografia de um homem jovem, negro, sentado à mesa e segurando um lápis em cima de um desenho, que nada mais é do que uma planta de um imóvel (DOMINGUES, 2013). A imagem reporta à ideia de algumas profissões, como arquiteto, engenheiro, projetista ou, ainda, desenhista. Como vimos, toda a coleção apresenta na capa a imagem de uma pessoa, em um ambiente específico, relacionado ao conteúdo do livro. Neste caso, podemos nos perguntar por que, em um livro de matemática, há um homem na capa e não uma mulher? Será que um dos motivos pode ser porque, tradicionalmente, há no senso comum uma concepção de que as mulheres não são competentes nas matérias das áreas "ditas" exatas?

A obra aborda os principais conteúdos da disciplina de matemática dos anos finais do Ensino Fundamental, incluindo, portanto, conteúdos básicos como os números naturais e as operações básicas com esses números, e com capítulos sobre frações, geometria, medidas, álgebra e equações.

No texto de apresentação do livro, a autora demonstra que o seu objetivo com a obra é "mostrar a você que a Matemática está presente em nosso dia a dia" (DOMINGUES, 2013, p. 3). Provavelmente, em vista disso, há um capítulo específico no livro chamado "Tratamento da Informação", que aborda leitura e interpretação de gráficos. Realmente, em toda a obra, existem muitos exercícios baseados em situações do cotidiano, o que não quer dizer que as abordagens sobre esse cotidiano sejam de forma inclusiva para as mulheres.

De forma geral, o livro utiliza uma linguagem masculinizada, invisibilizando as mulheres como partícipes da sociedade. Isso ocorre quando, por exemplo, em um exercício sobre a construção histórica da matemática, afirma-se que, "para ampliar seus conhecimentos sobre a história dos homens a construção do conhecimento matemático, pesquise em livros, em revistas ou na internet sobre os povos sumérios, egípcios, hindus, babilônios, maias, gregos, romanos ou árabes [...]" (DOMINGUES, 2013, p. 9 , grifo nosso). Isso também acontece quando a intenção é se referir à docente da turma, que é sempre um homem. Mesmo nas atividades práticas propostas, a turma é sempre convidada a questionar "seu educador" (DOMINGUES, 2013, p. 44) sobre o conteúdo. "Converse com seus colegas e com seu educador a respeito do assunto" (DOMINGUES, 2013, p. 60). No que se refere às/aos estudantes, a situação é a mesma, como quando afirma: "Solicite aos educandos que meçam a altura e o diâmetro" (DOMINGUES, 2013, p. 150).

Sobre os exercícios e problemas que o livro traz, a obra está "lotada" de exemplos onde se percebe a manutenção da lógica patriarcal e machista da sociedade contemporânea ocidental. De forma geral, neste livro se perpetuam as construções tradicionais do masculino e do feminino, relacionando cada um a atividades tradicionalmente consideradas de um gênero ou de outro.

Por exemplo, há um problema matemático que começa com o seguinte enunciado: "Joaquim e Pedro estão numa fila em que há 11 caminhões para descarregar no porto [...]" (DOMINGUES, 2013, p. 15). Independentemente da questão matemática, é bem provável que os dois homens da situação sejam caminhoneiros. Sabemos que essa profissão é tradicionalmente considerada mais masculina do que feminina, embora saibamos que essa situação timidamente já tenha mostrado avanços, pois já há mulheres caminhoneiras. Esse aspecto demonstra que o livro não problematiza essas representações conservadoras das profissões "ditas" masculinas. 
Há outro problema matemático a salientar. 0 enunciado, com o intuito de apresentar um exemplo de subtração, começa da seguinte forma: "O professor Édson estava indo para a escola quando o marcador de combustível do seu carro acendeu, indicando que havia no tanque somente o combustível reserva [...]" (DOMINGUES, 2013, p. 24). Esse exemplo presente na obra traz, em sua constituição, dois elementos para problematizarmos as questões de gênero. Um deles se refere à utilização de uma figura masculina como docente, sabendo-se que a profissão docente tem sido, de forma geral, majoritariamente constituída por mulheres. Portanto, mesmo que a intenção fosse reproduzir a representação majoritária da profissão, sem questionar sua constituição, teria que ser utilizada uma mulher nessa profissão. Salta aos olhos o fato de isso não ter acontecido aqui, mesmo a autora da obra sendo uma mulher. 0 outro aspecto desse exemplo a ser ressaltado se refere à atividade que o docente está realizando: dirigindo um carro. Embora muitas mulheres também exercerem essa atividade, sabemos que, desde a tenra infância, os meninos são bem mais instigados a isso do que as meninas, pois um dos principais "brinquedos" dos meninos são carrinhos. Dessa forma, desde a infância se instaura um processo pedagógico que se materializa em aprendizados de determinadas atividades que serão incentivadas socialmente, mesmo que de forma lúdica a princípio, mas que, com o tempo, se materializam de forma real. Lagarde y de Los Rios (2005), em sua obra, aborda os aprendizados infantis como um processo fundamental na construção dos gêneros, tanto masculinos como femininos.

Dos muitos exemplos de situações que o livro traz que reforçam os estereótipos de gênero, destaco a situação-problema a seguir: "A doceira Sandra cobra $\mathrm{R} \$ 24,00$ pelo quilograma de bolo de frutas. Ela recebeu uma encomenda de um bolo de 13 quilogramas. Quanto custará esse bolo?" ((DOMINGUES, 2013, p. 31). 0 exemplo mostra uma atividade profissional diretamente vinculada ao espaço doméstico e à cozinha. Neste exemplo, temos uma doceira mulher, o que demonstra claramente o vínculo entre o gênero e a atividade. É importante salientar que todas as situações apresentadas no livro que se referem à elaboração de alimentos (doces, salgados, receitas etc.) trazem figuras femininas. Em outro exemplo, o enunciado diz o seguinte: "Dona Ângela está fazendo salgados para entregar na cantina da escola [...]" (DOMINGUES, 2013, p. 143). No entanto, quando se trata do consumo de alimentos, a figura masculina é trazida à tona, como nos exemplos a seguir: "Carlos foi almoçar em um restaurante de massas que serve quatro tipos de macarrão [...] Carlos deve escolher um tipo de macarrão e um tipo de molho [...]" (DOMINGUES, 2013, p. 35); "Davi comeu dois pastéis de carne e um de queijo, tomou um refrigerante e comprou um copo de água mineral [...]" (DOMINGUES, 2013, p. 83). Assim, quanto ao consumo e à opção, a liberdade de escolha é masculina.

Outro exemplo a destacar aborda as relações de poder e mando nas profissões. A situação-problema diz o seguinte: "0 refeitório de uma escola está sendo reformado e as mesas serão trocadas. 0 diretor da escola optou por comprar mesas com 6 cadeiras [...]" (DOMINGUES, 2013, p. 33). Nessa situação, o espaço de liderança e mando da escola (a direção) é ocupada por um homem, mesmo sabendo-se que o espaço escolar é mais ocupado por profissionais mulheres do que homens. Em outro enunciado: "O prefeito de uma cidade iniciou há dois meses a reconstrução de uma avenida, trocando o asfalto velho por concreto [...]" (DOMINGUES, 2013, p. 55). Aqui também aparece um homem exercendo uma posição política de destaque e de exercício do poder.

Sobre o trabalho doméstico, os exemplos e as situações que o livro traz reforçam os estereótipos de gênero. Vejamos a seguinte situação-problema: "Três irmãos se associam, em partes iguais, na compra de uma lavadora de roupas para presentearem a mãe [...]" (DOMINGUES, 2013, p. 41). Aqui aparece uma relação 
direta entre a figura feminina e materna com um eletrodoméstico. Aqui percebe-se que aos homens é reservado o poder de consumo e de escolha, e à mulher-mãe cabe utilizar o produto nos afazeres domésticos.

Sobre as atividades vinculadas ao cuidado, uma situação-problema traz o seguinte enunciado: "Lúcia adquiriu um remédio genérico cujo preço de tabela é [...]" (DOMINGUES, 2013, p. 92). Aqui vemos reforçado o papel feminino como cuidadora, a pessoa que vai se dedicar aos medicamentos.

Sobre os espaços públicos e privados, o livro traz diversas situações-problema. Aqui destacamos uma situação que começa com o seguinte enunciado: "Marcelo costuma correr $12 \mathrm{~km}$ ao redor do quarteirão [...]" (DOMINGUES, 2013, p. 125). Para pesquisadoras feministas como Célia Amorós (1994), Perrot (2007) e Colling (2014), o espaço público foi historicamente dedicado aos homens, enquanto à mulher coube sua atuação nos espaços privados e domésticos. Embora admitamos que o espaço doméstico é um lócus de produção e de conhecimento, é inegável que, historicamente, essa posição social invisibilizou os fazeres femininos.

Sobre as imagens, nas poucas que o livro traz onde aparecem pessoas, a imensa maioria é de homens, inclusive em destaque, como na capa do segundo capítulo, onde aparece um homem de costas desenhando e calculando em um grande quadro de giz.

\section{Sobre o livro de Artes: a valorização da cultura popular e da arte enquanto utilidade}

O livro de artes possui três autores, sendo um homem e duas mulheres (SCHLICHTA; AZOUBEL; ROMANELLI, 2013). A capa do livro é ilustrada com uma grande fotografia de um homem jovem, branco, representando um ceramista esculpindo um vaso de argila. Atrás dele aparece uma estante com vários vasos e potes de argila. Sabemos que toda a coleção apresenta na capa a imagem de uma pessoa, em um ambiente específico, relacionado ao conteúdo do livro.

Na apresentação do livro, já é possível perceber a sua intenção: “[...] a ideia é que você possa ver como a arte pode ter uma relação rica com suas experiências de vida". (SCHLICHTA; AZOUBEL; ROMANELLI, 2013, p. 3). Dessa forma, o livro foi elaborado na perspectiva de abordar a arte como forma de participação das pessoas no mundo, fazendo parte da vida cotidiana de todas as pessoas. No sumário do livro, é possível identificar a intenção de desenvolver uma abordagem historicamente colocada da arte, mostrando a sua participação na história da humanidade desde os primórdios até os dias atuais.

De forma geral, o livro aborda diversas manifestações artísticas, como música, dança, escultura, pintura, desenho, entre outras. Há uma explícita valorização de culturas e manifestações populares, advindas especialmente do folclore brasileiro. O livro traz diversas propostas de atividades, instigando os/as estudantes ao exercício de criação.

A participação de mulheres pioneiras na produção cultural do Brasil revela conquistas de emancipação feminina, tanto no campo da produção intelectual como no campo do trabalho. Abordar o tema da participação feminina na produção artística brasileira e inserir o campo artístico nas muitas faces do longo processo de emancipação das mulheres é um desafio que ainda falta ser assumido.

Em razão da configuração social do país no final do século XIX e no início do século XX, as primeiras mulheres que puderam fazer parte do mercado cultural do país foram mulheres da elite. Sabemos que dedicar-se a uma atividade artística implica ter disponibilidade de tempo, o que as mulheres das classes populares não tinham, já que precisavam empenhar-se em atividades que possibilitassem seu sustento imediato e de suas famílias. Dessa forma, “[...] não é de se espantar que, se algumas mulheres conseguiram romper a barreira doméstica e se lançaram no mercado artístico, provinham de 
famílias que podiam dividir as tarefas domésticas com escravas ou empregadas." (QUEIROZ, 2016, p. 36).

Além disso, não podemos esquecer a hegemonia de concepções de arte conservadoras que, historicamente, valorizaram as produções elitizadas, menosprezando e desqualificando os saberes populares. Assim, o papel da mulher na história da Arte durante o século XIX nada mais é do que a expressão de sua condição de submissão, em que o masculino é que ditava as regras. Quando a mulher aparecia no campo da arte, ela normalmente era o tema da obra e não a autora. No caso das mulheres brasileiras,

[...] por longos anos até o acesso à aprendizagem técnica da pintura na escola de mais alto prestigio lhes era vedado: no Brasil, a permissão para a entrada de mulheres na Academia Imperial de Belas Artes só se deu em 1879, e com restrições, pois a elas era vedada a prática de desenho natural com modelo nu. Sob o ideal de preservar a honra das mulheres de 'boas famílias', dificultava-se o aprimoramento da técnica da pintura corporal. (QUEIROZ, 2016, p. 36, grifo do autor).

Sobre a abordagem de gênero - especialmente de mulheres - que o livro traz, existe uma seção denominada Biografia, que apresenta dados biográficos de artistas importantes no tema abordado no capítulo ao qual se refere. Ao todo, o livro possui 16 capítulos, e a maioria deles apresenta, no mínimo, duas biografias, podendo ser mais. Desse total de biografias apresentadas, 18 foram de artistas homens e apenas 5 de artistas mulheres, a maioria constante no capítulo 14 do livro, denominado Mulheres que entraram para a História. Aqui percebemos que as mulheres artistas ficam praticamente restritas a um capítulo específico sobre elas. Isso pode ser visto de duas formas: por um lado, pode ser positivo, pois dá visibilidade à participação e importância das mulheres na história e no mundo da arte; por outro lado, pode ser ruim, pois retira das mulheres a participação em temas tratados em outros capítulos do livro, onde elas historicamente existiram, mas que a estrutura do texto invisibilizou.
Em um livro de artes que buscou enfocar a produção artística nacional, buscando um afastamento de uma concepção de arte elitista, incorporando elementos da cultura popular e do folclore, foi possível perceber alguns silenciamentos quanto a produções de mulheres artistas brasileiras. Podemos citar, como exemplo, a arte da pintora brasileira Djanira da Motta e Silva. Para Gomes (2016, p. 31),

A força das obras de Djanira está em retratar as cenas mais simples com lirismo, respeito e curiosidade de antropóloga. [...]. Para além de seu comprometimento em retratar o proletariado, uma verve lúdica e permeada por sua insaciável curiosidade de abordar cenas do mundo do lazer - merecido momento de descanso do trabalhador - que se apresentam através do mundo do circo, dos parques de diversão, dos jogos de futebol, do dominó e das brigas de galo.

Outro silenciamento se refere à obra de Georgina de Albuquerque, que foi uma das precursoras da pintura impressionista no Brasil, juntamente com os pintores Eliseu Visconti, Antônio Parreiras e Lucílio de Albuquerque. Georgina foi a primeira mulher a pintar um quadro de temática histórica no país e a primeira diretora da Escola Nacional de Belas Artes.

Outro exemplo que podemos citar se refere à importância da obra de Patrícia Rehder Galvão, mais conhecida por Pagu, que vai do jornalismo à literatura, passando por uma intensa participação política na militância comunista. Pagu foi a primeira mulher brasileira presa por motivos políticos. Foi detida 23 vezes, chegando a permanecer presa por quatro anos. Autora de diversos romances, como jornalista foi uma grande divulgadora da cultura, tanto nacional como internacional. Era uma mulher que estava à frente de seu tempo (ASSIS; SANTOS, 2016).

\section{Entre continuidades e rupturas: considerações finais}

No que se refere aos discentes da modalidade de educação de jovens e adultos, "Conforme descrito pela proposta curricular para 
EJA, jovens e adultos dessa modalidade vêm de classes sociais pobres e não tiveram acesso à educação na idade própria, na maioria das vezes pela necessidade de entrar precocemente para o mercado de trabalho." (SILVA; VILLELA, 2016, p. 1-2).

Não se pode afirmar que apenas o uso de livros didáticos adequados seja a garantia da formação de pessoas conscientes e atuantes nos espaços sociais. Entretanto, sabemos que os livros didáticos são importantes ferramentas (senão as principais) utilizadas nas e pelas escolas.

De uma forma geral, a coleção de livros didáticos analisada mostra que os autores e autoras demonstraram uma preocupação de dar visibilidade aos saberes populares, aliando o conhecimento científico às práticas cotidianas, dando sentido e concretude ao conhecimento estudado. No entanto, no que se refere às questões sobre as mulheres, é possível perceber que faltam elementos para uma abordagem mais consistente da temática de gênero. A coleção mostra certo desconhecimento da produção advinda tanto da teoria feminista como da produção de mulheres cientistas em diversas áreas.

Dessa forma, o que percebemos é que as mulheres aparecem nos livros ainda de forma superficial e aleatória, o que pode acarretar uma manutenção do conservadorismo patriarcal e das estruturas de poder machistas tradicionais, como pudemos observar em diversas situações-problema apresentadas no livro de matemática, por exemplo.

Na intenção de identificar as representações de gênero, compreendendo-o na sua interseccionalidade com raça e classe social, em nossa investigação foi possível perceber que, mesmo com os avanços em legislações no que se refere ao combate à discriminação de gênero, raça e classe, ainda se mantêm abordagens conservadoras e discriminatórias, mesmo que de forma bastante sutil, o que demonstra a naturalização de desigualdades sociais. As categorias classe social e raça são demasiadamente invisibilizadas nas abordagens e conteúdos trazidos pelos livros, embora saibamos que o currículo envolve escolhas, onde estão presentes relações de poder e visões de mundo específicas que incorporam determinados grupos e excluem outros.

Nos livros analisados, a questão de desigualdades econômicas e sociais aparece de forma mais contundente nos livros de história, geografia e artes. No livro de história, a intenção de dar visibilidade aos povos tradicionais e às disputas por poder e território no país trazem à tona as desigualdades sociais do povo brasileiro e as lutas sociais encampadas pelos movimentos. Dessa forma, há a incorporação das categorias classe e raça/etnia no livro, embora a categoria gênero esteja bem mais invisibilizada.

No livro de geografia, também foi possível identificar abordagens sobre os povos tradicionais na constituição da população do país. Além disso, o livro trata de aspectos referentes ao mundo do trabalho, mostrando a participação desigual das mulheres no mercado de trabalho do Brasil e do mundo.

Como vimos, no livro de artes houve a preocupação de abordar a arte vinculada ao cotidiano das pessoas comuns, aproximando a produção artística com a técnica, aliando a criação com a tecnologia na construção da arte não apenas como contemplação, mas como uma ferramenta importante na vida das pessoas. Para isso, trouxeram à pauta a cultura popular e o folclore. Essa perspectiva, por si só, já denota uma concepção de arte que se aproxima das classes populares.

Assim, é possível afirmar que a coleção analisada apresenta uma série de rupturas às concepções de conhecimento tradicionais, buscando aproximar os conhecimentos científicos que aborda com os saberes populares do público de EJA a que se destinam. No entanto, no que se refere às mulheres, podemos afirmar que ainda temos um longo caminho a trilhar, especialmente no que se refere ao gênero na forma de sua interseccionalidade com classe e raça/etnia. 


\section{REFERÊNCIAS}

AMORÓS, Cèlia. Feminismo: igualdad y diferencia. Ciudad de México: Universidad Nacional Autônoma de México, 1994. p. 21-52.

ASSIS, Maria Elisabete Arruda de; SANTOS, Taís Valente dos (Org.). Memória feminina: mulheres na história, história de mulheres. Recife: Fundação Joaquim Nabuco/Massangana, 2016.

BRASIL. Ministério da Educação. Definição de critérios para avaliação dos livros didáticos: Português, matemática, estudos sociais e ciências 1ㅁa a 4⿳⺈ séries. Brasília, DF: FAE/MEC/Unesco, 1994.

COLling, Ana Maria. Tempos diferentes, discursos iguais: a construção do corpo feminino na história. Dourados, MS: Editora da UFGD, 2014.

DOMINGUES, Luzia de Jesus. Educação de jovens e adultos: Alcance EJA: matemática: anos finais do ensino fundamental. Curitiba: Positivo, 2013.

DUDEQUE, Marcia L.; SAMPAIO, Elvira. Educação de jovens e adultos: Alcance EJA: ciências: anos finais do ensino fundamental. Curitiba: Positivo, 2013.

FRANCO, Maria Laura P. B. Análise de conteúdo. 4. ed. Brasília, DF: Liber Livro, 2012.

GOMES, Daniela Matera Lins. Djanira: cronista de ritos, pintora de costumes. In: ASSIS, Maria Elisabete Arruda de; SANTOS, Taís Valente dos (Org.). Memória feminina: mulheres na história, história de mulheres. Recife: Fundação Joaquim Nabuco/Massangana, 2016. p. 27-33.

GRITTEM, Silvana. Educação de jovens e adultos: Alcance EJA: geografia: anos finais do ensino fundamental. Curitiba: Positivo, 2013.

IGNOTOFSKY, Rachel. As cientistas: 50 mulheres que mudaram o mundo. São Paulo: Blucher, 2017.

INSTITUTO BRASILEIRO DE GEOGRAFIA E ESTATÍSTICA (IBGE). Estatística. Multidomínio. Gênero. Brasília, DF, 2017. Disponível em: <https:// www.ibge.gov.br/estatisticas-novoportal/ multidominio/genero.html>. Acesso em: 20 out. 2017.

LAGARDE Y DE LOS RÍOS, Marcela. Os cativeiros de las mujeres. México: UNAM, 2005.

LOBO, Andréa. Educação de jovens e adultos: Alcance EJA - história: anos finais do ensino fundamental. Curitiba: Positivo, 2013.

MARQUES, Mara Rúbia. Imagens femininas e masculinas no livro didático: subsídios para um debate teórico-metodológico. In: MELO, Hildete. Et al. (Org.). Olhares feministas. Brasília, DF: Ministério da Educação/UNESCO, 2006. p. 209-221.

McGRAYNE, Sharon Bertsch. Mulheres que ganharam o Prêmio Nobel em Ciências. São Paulo: Marco Zero, 1994.

MINISTÉRIO DA EDUCAÇÃO. Fundo Nacional de Desenvolvimento da Educação. Programas do livro. Brasília, DF, 2013. Disponível em: <http:// www.fnde.gov.br/programas/programas-do-livro/ livro-didatico/historico>. Acesso em: 10 jun. 2017.

MINISTÉRIO DA MULHER, DA FAMÍLIA E DOS DIREITOS HUMANOS. Relatório Anual Socioeconômico da Mulher (RESEAM). Brasília, DF, 2015. Disponível em: <http://www.spm.gov.br/centralde-conteudos/publicacoes/publicacoes/2015/ livro-raseam_completo.pdf>. Acesso em: 25 ago. 2017.

PEGURIER, Eduardo. Sylvia Earle: precisamos parar a "mineração" do oceano. ((0)) eco, Rio de Janeiro, 06 abr. 2015. Seção Notícias. Disponível em: <http://www.oeco.org.br/reportagens/29033sylvia-earle-precisamos-parar-a-mineracao-dooceano/>. Acesso em: 01 nov. 2017.

PERROT, Michelle. Minha história das mulheres. São Paulo: Contexto, 2007.

QUEIROZ, Eneida. Georgina de Albuquerque e a pintura impressionista no Brasil. In: ASSIS, Maria Elisabete Arruda de; SANTOS, Taís Valente dos (Org.). Memória feminina: mulheres na história, história de mulheres. Recife: Fundação Joaquim Nabuco/Massangana, 2016. p. 35-43.

ROSEnTHAL, Gabriele. Pesquisa social interpretativa: uma introdução. 5. ed. Porto Alegre: EDIPUCRS, 2014.

SCHIENBINGER, Londa. 0 feminismo mudou a ciência? Bauru, SP: EDUSC, 2001.

SCHLICHTA, Consuelo; AZOUBEL, Juliana; ROMANELLI, Guilherme. Educação de jovens e adultos: Alcance EJA: artes: anos finais do ensino fundamental. Curitiba: Positivo, 2013.

SILVA, Janine Marta Pereira A. da; VILLELA, Ana Maria Nápoles. O livro didático na Educação de Jovens e Adultos (EJA): ferramenta para certificação ou para um processo de ensino e aprendizagem significativo? Pesquisas em Discurso Pedagógico, Rio de Janeiro, n. 1, p. 1-18, 2016. 
SILVA, Márcia Alves da; PINHEIRO, Renata Kabke. Representações de gênero em livros didáticos. Projeto de pesquisa. Pelotas, RS: UFPel, 2014.

SILVA, Paulo Vinicius Baptista da; TEIXEIRA, Rozana; PACÍfICO, Tânia Mara. Programas de distribuição de livros e hierarquias raciais: o que dizem os alunos negros/as? In: FERREIRA,
Aparecida de Jesus (Org.). As políticas do livro didático e identidades sociais de raça, gênero, sexualidade e classe em livros didáticos. Campinas, SP: Pontes, 2014. p. 23-46.

Recebido em: 15/12/2017 Aprovado em: 09/02/2019 